\title{
Acidification of the Skin and Maintenance of the Physiological Skin pH Value by Buffered Skin Care Products Formulated around pH 4
}

\author{
Anke Schulte to Brinke¹, Antje Mehlich ${ }^{2}$, Claudia Doberenz ${ }^{2}$, Ciska Janssens-Böcker ${ }^{1}$ \\ ${ }^{1}$ Department of Clinical Affairs MedSkin Solutions Dr. Suwelack AG, Billerbeck, Germany \\ ${ }^{2}$ Department of Innovation and Development MedSkin Solutions Dr. Suwelack AG, Billerbeck, Germany \\ Email: anke.schultetobrinke@medskin-suwelack.com, antje.mehlich@medskin-suwelack.com, \\ claudia.doberenz@medskin-suwelack.com, ciska.janssens-boecker@medskin-suwelack.com
}

How to cite this paper: Schulte to Brinke, A., Mehlich, A., Doberenz, C. and Janssens-Böcker, C. (2021) Acidification of the Skin and Maintenance of the Physiological Skin $\mathrm{pH}$ Value by Buffered Skin Care Products Formulated around $\mathrm{pH}$ 4. Journal of Cosmetics, Dermatological Sciences and Applications, 11, 44-57. https://doi.org/10.4236/jcdsa.2021.111005

Received: December 9, 2020

Accepted: March 9, 2021

Published: March 12, 2021

Copyright $\odot 2021$ by author(s) and Scientific Research Publishing Inc. This work is licensed under the Creative Commons Attribution International License (CC BY 4.0).

http://creativecommons.org/licenses/by/4.0/

\section{(c) (i) Open Access}

\begin{abstract}
Each biological system possesses a widely unrecognized buffer system to maintain acid-base balance to a specific $\mathrm{pH}$. The skin $\mathrm{pH}$ is crucial for physiological skin function. In aged or diseased skin, $\mathrm{pH}$ increase is observed and may negatively affect skin health. Skin care products with a $\mathrm{pH}$ that is slightly more acidic than the average normal skin $\mathrm{pH}$ and have an adequate buffering capacity, are considered beneficial for the skin. However, the buffer capacity of these products also plays an important role. In the present study, a possible normalization or acidification of skin surface $\mathrm{pH}$ and influence on skin hydration and skin barrier function was assessed via application of buffered skin care products that are formulated with $\mathrm{pH} \leq 4.5$. 48 subjects aged above 50 were treated with three different skin care products (Vitamin C Spheres, Collagen Spray, and Collagen Mask) and skin surface $\mathrm{pH}$, skin hydration and barrier integrity were assessed before treatment start and after 4 weeks. The results show that after 4-week treatment with Vitamin $\mathrm{C}$, the skin $\mathrm{pH}$ is acidified. Treatment with Collagen Spray and Collagen Mask showed maintenance of a physiological skin $\mathrm{pH}$. Subgroup analysis of subjects that had a higher than average skin $\mathrm{pH}$ at study start demonstrated that all three tested skin care products were able to acidify the skin surface. In addition, skin hydration was also increased for two of the three tested products, whereas skin barrier is not significantly changed. This demonstrates that buffered skin care products formulated to a $\mathrm{pH} \leq 4.5$ are able to acidify and maintain physiological skin $\mathrm{pH}$ and may contribute to a physiological skin function.
\end{abstract}

\section{Keywords}

Skin pH, Buffer Capacity, Skin Care, Skin Aging, Acidification 


\section{Introduction}

Each biological system possesses a widely unrecognized buffer system to maintain acid-base balance to a specific $\mathrm{pH}$ [1]. $\mathrm{pH}$ is an important physiochemical factor that plays a significant role in various metabolic, molecular and cell-regulating processes. Especially in the stratum corneum, the $\mathrm{pH}$ value is of great importance for the physical, chemical and microbiological barrier function [2] [3] [4] [5]. A variety of skin $\mathrm{pH}$ values are being reported in literature. The "normal" $\mathrm{pH}$ value of the skin surface of most parts of the body is moderately acidic and in the range of $\mathrm{pH} 4.1-5.8$ (arithmetic mean 4.9) [6]. Measurement of the acidity of the skin surface can be done according to 2 criteria-its value given by the $\mathrm{pH}$ and its strength determined by the skin's ability to resist acid/alkaline aggression, which is called buffer capacity [7].

Skin surface $\mathrm{pH}$ is influenced by many physiological and environmental factors. Skin surface $\mathrm{pH}$ differs with age, gender, race, anatomical position, circadian rhythm, the amount of sebum on the skin, skin moisture and sweating [8]. Many exogenous factors such as occluded skin, exposure to skin irritants such as soaps and detergents, and skin washing affect skin $\mathrm{pH}$. Additionally, application of cosmetic product affects skin $\mathrm{pH}$ as well, because many cosmetic products have a higher $\mathrm{pH}$ value than the normal natural skin $\mathrm{pH}$ and lead to an increased skin $\mathrm{pH}$, higher than natural skin $\mathrm{pH}$ [9]. But also the use of plain tap water, in Europe with a $\mathrm{pH}$ value generally around 8.0, will increase skin $\mathrm{pH}$ up to $6 \mathrm{~h}$ after application before returning to its "natural" value of on average below 5.0 [10].

$\mathrm{pH}$ and buffer capacity regulate stratum corneum (SC) barrier, are involved with the activation of various enzymes and influence epidermal differentiation and desquamation [1]. The acid surface $\mathrm{pH}$ is an important determinant of the growth conditions of both the resident microflora, i.e. those normally present on the skin, and the transient microflora, i.e. opportunistic, potentially pathogenic [11] [12]. Changes in skin $\mathrm{pH}$ from acidic to alkaline are also related to the development of cutaneous skin diseases such as atopic dermatitis [13]. Reducing the $\mathrm{pH}$ (skin acidification) of the skin has been suggested as a therapeutic or preventive strategy in skin diseases with an impaired epidermal barrier function like atopic dermatitis or acne vulgaris [1] [14] [15]. Disruption of skin barrier by tape-stripping has been demonstrated to increase skin $\mathrm{pH}$ in hairless mouse skin. Furthermore, the application of an acid solution with an appropriate buffer capacity after barrier disruption by tape stripping leads to less increase in $\mathrm{pH}$ than after the application of neutral or alkaline solution [1] [16].

Therefore, various aspects must be taken into account when developing a skin care product. In addition to the chemical stability of the ingredients and the formulation itself, not only the absolute $\mathrm{pH}$ value but also the buffer capacity is of crucial importance. The buffer capacity describes the ability of a formulation to keep the $\mathrm{pH}$ value almost constant under the influence of acidic or alkaline stressors [9]. 
In this context, the maintenance of physiological skin $\mathrm{pH}$ conditions and, if necessary, the correction (skin acidification) of $\mathrm{pH}$, by topically applied cosmetic formulations could be of relevance in supporting skin function and protection. In this study, we analyzed the long lasting effect of three cosmetic products on skin $\mathrm{pH}$, hydration and barrier and assessed whether these products could protect and maintain a physiological skin $\mathrm{pH}$ to support skin function and protection.

\section{Material and Methods}

\subsection{Tested Products}

The following test products (Medskin Solutions Dr. Suwelack AG, Germany) were used based on the instructions for use.

Vitamin C Spheres (Vit C) is a freeze-dried product consisting of 79\% L-ascorbic acid, which is freshly activated with a buffered activating liquid (aqua, glycerin, 1,5-pentanediol, sodium lactate, lactobacillus ferment) to maintain a correct $\mathrm{pH}$ of the product.

Collagen Spray (Spray) is a spray consisting of bovine native collagen molecules (main ingredients: soluble collagen, glycerin, pyrrolidonecarboxylic acids, saccharide isomerate, panthenol, monosodium citrate, citric acid sodium citrate).

Collagen Face Mask (Mask) is a freeze-dried mask consisting of bovine native collagen fibers, molecules and peptides, freshly activated with an activating liquid (main ingredients: butylene glycol, glycerin, sodium lactate, lactic acid, saccharide isomerate, pullulan, allantoin, sodium citrate, citric acid).

\subsection{Determination of Product $\mathrm{pH}$ and Product Buffer Capacity}

Vit $\mathrm{C}$ and masks were activated according to their recommended application procedure before measuring the $\mathrm{pH}$ values. After $20 \mathrm{~min}$ of incubation the aqueous phase was prepared for measurements described below. Liquids and Spray were used as original formulation.

The $\mathrm{pH}$ was measured electrochemically with a $\mathrm{pH}$ meter (type inoLab $\mathrm{pH}$ 730). The electric potential, which is directly dependent on the hydrogen ion concentration, is measured with a glass electrode.

Following Oman et al. [17], defined concentrations of $\mathrm{NaOH}$ or HCL were added to the aqueous phase, and shifts in $\mathrm{pH}$ were measured. Aqueous phase measuring $2 \times 10 \mathrm{~mL}$ was aliquoted into separate tubes and successively titrated with $10 \mathrm{ml} 0.1 \mathrm{~N} \mathrm{NaOH}$ solution or $10 \mathrm{ml} 0.1 \mathrm{~N} \mathrm{HCl}$ solution in which the $10 \mathrm{ml}$ final volume was titrated in different aliquots. The $\mathrm{pH}$ value was measured after each addition and homogenous mixing. The buffer capacity of the preparations was calculated as follows:

$$
\beta=\frac{1}{\mathrm{pH}(2.5 \mathrm{~mL} 0.1 \mathrm{~N} \mathrm{NaOH})-\mathrm{pH}(2.5 \mathrm{~mL} 0.1 \mathrm{~N} \mathrm{HCl})}
$$




\subsection{Randomized Single Center Study}

The study was conducted at proDERM GmbH, Hamburg, Germany in 2020. Treatment products were randomly allocated to the volar forearm of 48 subjects (female and male) aged 50 and above with healthy skin. The effect of the 3 test products on the skin barrier, skin hydration and skin $\mathrm{pH}$ was determined by intra-individual comparison over a time period of 29 days. The untreated area was randomly assigned to one of the forearms of each subject. On the remaining two test areas on the other forearm each subject got a randomized subset of two out of the three test products (Figure 1), so that for each treatment 24 observations are obtained and all pairwise treatment combinations occur similarly often. Randomization was recorded appropriately.

Prior to study start a written and dated full approval was obtained from an independent institutional review board (IRB, proDERM GmbH) and informed consent was obtained from all study subjects. The study was conducted according to the Study Protocol and GCP principles.

The subjects were instructed not to apply any detergents (e.g. soaps, shampoos, bath and shower products) in the test area within the last 24 hours prior to the start of the study and within the last 24 hours prior to the instrumental measurements. Subjects applied the test products in the test area not earlier than 15 minutes after showering.

\subsubsection{Climatic Conditions}

The instrumental measurements took place in an air-conditioned room at a temperature of $21^{\circ} \mathrm{C} \pm 1^{\circ} \mathrm{C}$ and at $50 \% \pm 5 \%$ relative humidity. Before measurements, the subjects stayed in the climatized room for at least 30 minutes.

\subsubsection{Skin Hydration}

The measurement of stratum corneum hydration was performed by the electrical capacitance method with the CORNEOMETER CM 825 (Courage \& Khazaka, Cologne, Germany). The measuring principle is based on changes in the capacity of the measuring head, functioning as a capacitor. Between the conductors consisting of gold, an electrical field is built. By these means, the dielectricity of the upper skin layer is measured. Because the dielectricity varies as a function of the skin's water content, the stratum corneum hydration can be measured.

\subsubsection{TEWL Measurement}

TEWL was measured with TEWAMETER ${ }^{\circledast}$ TM 300 (Courage \& Khazaka, Cologne, Germany). Transepidermal water loss (TEWL) is a non-invasive method to measure the barrier function of the skin and is regarded as a sensitive parameter to quantify skin barrier damage.

The probe was held in place for each measurement for 30 seconds. This was to assure that a stable value had been established. The first part of the measurements belonged to this equilibration phase. The values of the last 10 seconds ( $=10$ values) were averaged as the actual measurement value. 


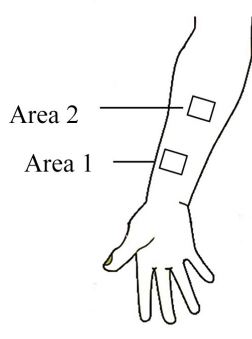

RIGHT

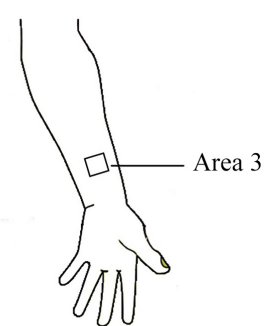

LEFT

Figure 1. Scheme of intra-individual treatment randomization. The untreated area was randomly assigned to one of the forearms of each subject. On the remaining two test areas on the other forearm each subject got a randomized subset of two out of three test products.

\subsubsection{Skin $\mathrm{pH}$}

For $\mathrm{pH}$ measurements, the SKIN PH METER PH 900 PC, (Courage \& Khazaka, Cologne, Germany) was used with a flat glass electrode.

\subsubsection{Statistical Data Analysis}

A significance level of 0.05 (alpha) was chosen for statistical analysis. Pairwise comparison of assessment times was performed on raw data with paired t-Test for each treatment and parameter separately. The computation of the statistical data was carried out with commercially available statistics software (SAS for Windows).

\section{Results}

\subsection{Determination of Product pH and Buffer Capacity}

The tested products and their respective $\mathrm{pH}$ values and buffer capacities are shown in Table 1.

\subsection{Application of Preparations for 4 Weeks}

46 subjects completed the study. Two subjects missed the final visit and were excluded from data analysis. One subject was excluded from data analysis due to a protocol deviation. The remaining subject population analyzed $(89.6 \%$ female, $10.4 \%$ male) had a mean age of 59.2 years. Mean values and standard deviation for skin hydration, TEWL and skin $\mathrm{pH}$ measurements are summarized in Table 2.

At baseline, the mean skin $\mathrm{pH}$ of all test areas on the volar forearm was 4.99 (range, 4.87 - 5.08) and the values for skin $\mathrm{pH}$ in the test areas were homogenous. A significant decrease of the mean skin $\mathrm{pH}$ was observed after 4 weeks of treatment with Vit $C$ (baseline vs day $29,5.09 \pm 0.51$ vs. $4.67 \pm 0.38, \mathrm{p}<0.05$ ) (Table 2 and Figure 2). In comparison to untreated control, this was statistically significant different $(\mathrm{p}<0.05)$ at day 29. Treatment with the Mask decreased skin $\mathrm{pH}$ (baseline vs day $29,5.05 \pm 0.56$ vs. $4.89 \pm 0.38, \mathrm{p}=0.101$ ), treatment with Spray maintained skin pH (baseline vs day $29,4.87 \pm 0.56$ vs. $4.82 \pm 0.41, \mathrm{p}$ $=0.482$ ). No statistical significance was found between application of Spray or Mask to untreated control areas. 
Table 1. Tested products for $\mathrm{pH}$-value and buffer capacity.

\begin{tabular}{ccc}
\hline Product & pH-value & buffer capacity \\
\hline Vit C + Activation Liquid & 3.59 & 4.0000 \\
Spray & 3.77 & 0.7692 \\
Mask + Activation Liquid & 4.33 & 1.8519 \\
\hline
\end{tabular}

Table 2. Skin surface pH, TEWL and skin hydration of the test and control areas at day 1 (before application) and day 29 (after application for 4 weeks).

\begin{tabular}{|c|c|c|c|c|c|c|}
\hline & \multicolumn{2}{|c|}{ Hydration } & \multicolumn{2}{|c|}{ TEWL } & \multicolumn{2}{|c|}{$\mathrm{pH}$} \\
\hline & Day 1 & Day 29 & Day 1 & Day 29 & Day 1 & Day 29 \\
\hline untreated & $38.01 \pm 6.13$ & $36.85 \pm 6.49$ & $11.9 \pm 3.7$ & $12.9 \pm 2.5^{\star}$ & $4.94 \pm 0.50$ & $4.87 \pm 0.43$ \\
\hline Vit C & $37.21 \pm 6.32$ & $36.94 \pm 5.63$ & $11.6 \pm 4.1$ & $12.9 \pm 2.0$ & $5.08 \pm 0.49$ & $4.67 \pm 0.38^{\star} \dagger$ \\
\hline Spray & $37.03 \pm 6.69$ & $41.67 \pm 6.59^{*} \dagger$ & $10.5 \pm 2.4$ & $13.9 \pm 5.7^{\star}$ & $4.87 \pm 0.55$ & $4.82 \pm 0.41$ \\
\hline Mask & $37.94 \pm 8.03$ & $39.65 \pm 6.98 \dagger$ & $11.9 \pm 4.7$ & $13.6 \pm 2.5$ & $5.05 \pm 0.56$ & $4.89 \pm 0.38$ \\
\hline
\end{tabular}

Absolute values, mean \pm standard deviation $(\mathrm{SD}) .{ }^{*} \mathrm{p}<0.05$ compared with day $1, \dagger \mathrm{p} \leq 0.05$ compared to control area at day 29 .

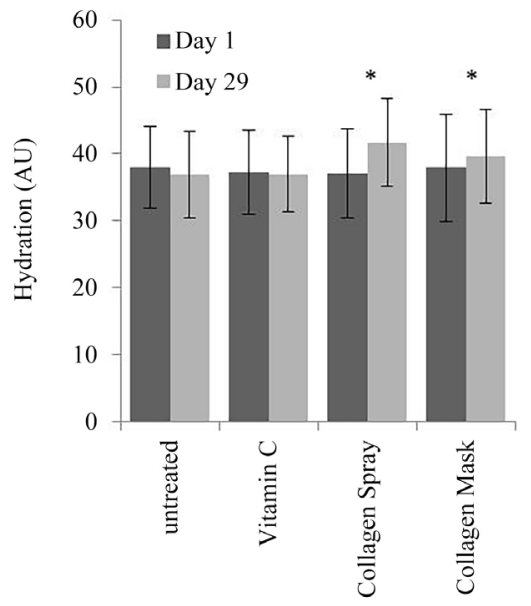

Figure 2. Skin surface given by the mean values \pm SD on the untreated area and treated area at baseline (Day 1 ) as well as 28 days thereafter. ${ }^{\star} \mathrm{p} \leq 0.05$ : Significantly different from day 1 (baseline).

For subjects with an already increased skin $\mathrm{pH}>5$ at baseline $(\mathrm{n}=30)$, a reduction in skin $\mathrm{pH}$ was observed for all three products (Table 3 ). The highest reduction was observed with Vit $C$ (baseline vs day $29,5.5 \pm 0.35$ vs. $4.77 \pm 0.41$, $\mathrm{p}<0.05$ ). The Spray significantly reduced skin $\mathrm{pH}$ by $0.37 \pm 0.48$ units (baseline vs day $29,5.60 \pm 0.46$ vs. $5.23 \pm 0.38, \mathrm{p}<0.05)$. The Mask reduced skin $\mathrm{pH}$ by $0.41 \pm 0.36$ (baseline vs day $29,5.43 \pm 0.38$ vs. $5.01 \pm 0.35$ ). In a subgroup analysis of subjects with a baseline $\mathrm{pH}<5.0$ (Table 4), a non significant slight decrease in skin $\mathrm{pH}$ was observed for Vit C (baseline vs day 29, $4.66 \pm 0.26$ vs. 4.58 \pm 0.32 ). For the Spray and Mask a non-significant slight increase skin $\mathrm{pH}$ (Spray: baseline vs day $29,4.61 \pm 0.25$ vs. $4.68 \pm 0.32$; Mask: baseline vs day $29,4.53 \pm$ 0.34 vs. $4.77 \pm 0.41)$.

At baseline, the values for skin hydration were homogeneous in the test areas. After 4 weeks of treatment, the overall skin hydration was increased for Spray and 
Mask but not for untreated skin and Vit C (Table 2 and Figure 3). The observed increase was significant for the Spray compared with day 1 and compared to untreated area. For the Mask, the increase was significant compared to control area.

The untreated area showed a significant increase in TEWL compared to day 1 (untreated: $11.9 \pm 3.7$ to $12.9 \pm 2.5$ ). A non-significant increase in mean TEWL values compared with control area was observed for all test products after 4 weeks of treatment (Vit C: $11.6 \pm 4.1$ to $12.9 \pm 2.0$; Spray: $10.5 \pm 2.4$ to $13.9 \pm 5.7$; Mask: $11.9 \pm 4.7$ to $13.6 \pm 2.5)$. For Spray, the difference in TEWL was significant compared to day 1 (Table 2 and Figure 4). In a subgroup analysis of subjects with an initial $\mathrm{pH}>5.0$ (Table 4), this effect is less pronounced (Table 4), whereas it was more pronounced in a subgroup analysis of subjects with an initial $\mathrm{pH}<5.0$ (Table 4$)$.

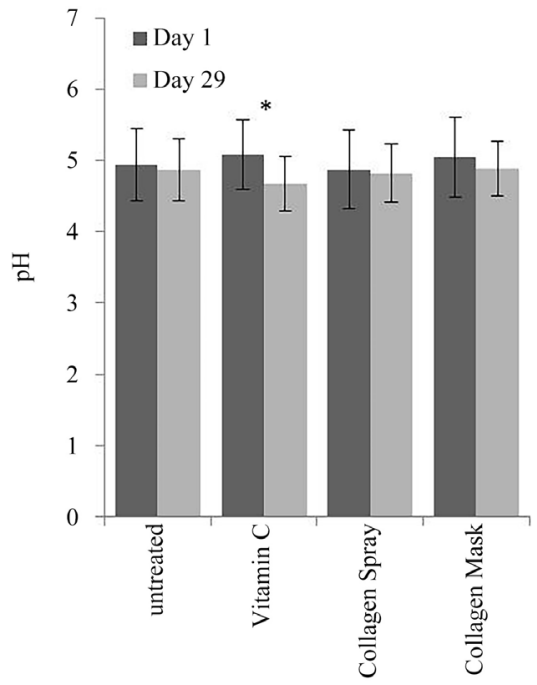

Figure 3. Skin hydration given by the mean values \pm SD on the untreated area and treated area at baseline (day 1 ) as well as 28 days thereafter. ${ }^{*} \mathrm{p} \leq 0.05$ : Significantly different from day 1 (baseline).

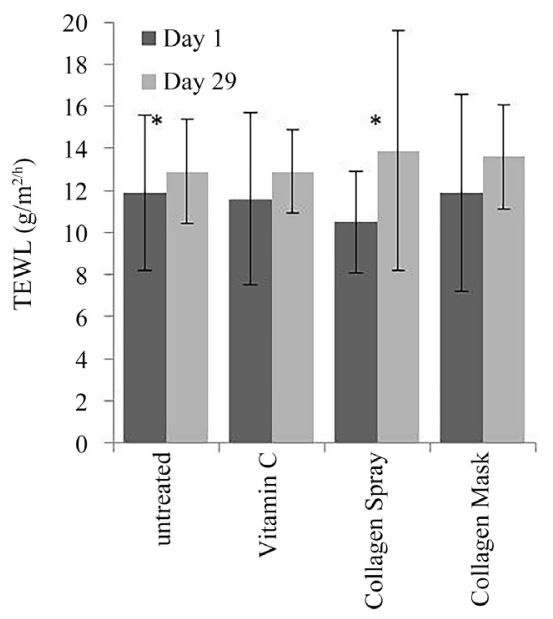

Figure 4. Transepidermal water loss given by the mean values \pm SD on the untreated area and treated area at baseline (day 1 ) as well as 28 days thereafter. ${ }^{*} \mathrm{p} \leq 0.05$ : Significantly different from day 1 (baseline). 
Table 3. Subgroup analysis $(\mathrm{pH}>5)$ for skin surface $\mathrm{pH}$, TEWL and skin hydration of the test areas at day 1 (before application) and day 29 (after application for 4 weeks).

\begin{tabular}{cccccccccc}
\hline & \multicolumn{3}{c}{ Hydration } & \multicolumn{3}{c}{ TEWL } & \multicolumn{3}{c}{ pH } \\
\cline { 2 - 10 } & Day 1 & Day 29 & Diff & Day 1 & Day 29 & Diff & Day 1 & Day 29 & Diff \\
\hline Vit C & $33.75 \pm 4.76$ & $34.82 \pm 4.19$ & $1.18 \pm 4.03$ & $12.04 \pm 4.96$ & $13.48 \pm 2.00$ & $1.40 \pm 3.89$ & $5.5 \pm 0.35$ & $4.77 \pm 0.41$ & $-0.69 \pm 0.43^{*}$ \\
Spray & $33.43 \pm 9.30$ & $39.04 \pm 4.68$ & $5.61 \pm 8.41$ & $10.17 \pm 2.78$ & $12.40 \pm 1.50$ & $2.23 \pm 2.86^{*}$ & $5.60 \pm 0.46$ & $5.23 \pm 0.38$ & $-0.37 \pm 0.48^{*}$ \\
Mask & $38.26 \pm 9.28$ & $39.17 \pm 6.43$ & $0.91 \pm 6.79$ & $12.19 \pm 5.54$ & $13.66 \pm 2.69$ & $1.46 \pm 4.74$ & $5.43 \pm 0.38$ & $5.01 \pm 0.35$ & $-0.41 \pm 0.36$ \\
\hline
\end{tabular}

Absolute values, mean \pm standard deviation $(\mathrm{SD})$. $^{*} \mathrm{p} \leq 0.05$ compared with day 1 ; Diff: mean difference day 1 vs day 29.

Table 4. Subgroup analysis $(\mathrm{pH}<5)$ for skin surface $\mathrm{pH}$, TEWL and skin hydration of the test areas at day 1 (before application) and day 29 (after application for 4 weeks).

\begin{tabular}{cccccccccc}
\hline & \multicolumn{3}{c}{ Hydration } & \multicolumn{3}{c}{ TEWL } & & \multicolumn{2}{c}{ pH } \\
\cline { 2 - 10 } & Day 1 & Day 29 & Diff & Day 1 & Day 29 & Diff & Day 1 & Day 29 & Diff \\
\hline Vit C & $41.13 \pm 5.71$ & $39.31 \pm 6.50$ & $-0.94 \pm 5.19$ & $10.98 \pm 3.24$ & $12.10 \pm 1.94$ & $0.71 \pm 2.17$ & $4.66 \pm 0.26$ & $4.58 \pm 0.32$ & $-0.11 \pm 0.32$ \\
Spray & $38.52 \pm 4.88$ & $42.74 \pm 7.07$ & $4.22 \pm 4.95$ & $10.62 \pm 2.23$ & $14.71 \pm 6.80$ & $4.09 \pm 6.39^{*}$ & $4.61 \pm 0.25$ & $4.68 \pm 0.32$ & $0.07 \pm 0.24$ \\
Mask & $37.46 \pm 6.07$ & $40.41 \pm 8.11$ & $2.96 \pm 4.94$ & $11.54 \pm 3.23$ & $13.53 \pm 2.41$ & $2.41 \pm 3.67$ & $4.53 \pm 0.34$ & $4.77 \pm 0.41$ & $0.23 \pm 0.21$ \\
\hline
\end{tabular}

Absolute values, mean \pm standard deviation (SD). ${ }^{*} \mathrm{p} \leq 0.05$ compared with day 1 , Diff: mean difference day 1 vs day 29.

\section{Discussion}

In the past, the generally accepted "neutral" skin pH range was between 5.4 and 5.9 and was advertised on many cosmetic product labels. More recent data demonstrates however that the "normal" $\mathrm{pH}$ of the skin surface of most body parts is moderately acidic in the range of $\mathrm{pH} 4.1-5.8$ with an arithmetic mean $\mathrm{pH}$ of 4.9 [18]. The $\mathrm{pH}$ value of the skin is important for the physical, chemical and microbiological barrier function [2] [3] [4] [19]. Against this background, the protection, maintenance and therapeutic correction (acidification) of physiological $\mathrm{pH}$ conditions by topically applied formulations could be a relevant treatment option [20] [21] [22] [23]. Therefore, we investigate the possible effect on skin $\mathrm{pH}$, barrier function and skin hydration by application of 3 different cosmetic products that are formulated with a low $\mathrm{pH}$ and proper buffer capacity.

Because product development is generally focused on product stability, it may happen that the optimal product $\mathrm{pH}$ is different from the physiologic skin surface $\mathrm{pH}$ (4.5 - 5.5) [9] [24] [25]. Shi et al. [24] determined the $\mathrm{pH}$ of 31 skin care products sold in the United States (2012). Eighteen products from different brands showed a $\mathrm{pH}$ between 5.5 and 8.2. In a recent investigation, Wohlrab and Gebert [9] determined the $\mathrm{pH}$ and the buffering capacity of 66 cosmetic skin care products from the German market. They considered both parameters as quality criteria for an optimized preparation for skin acidification. Only $43 \%$ of the evaluable products showed a $\mathrm{pH}$ of $<5.5$ and may therefore be considered appropriate for the treatment of skin with impaired barrier function or for topical skin acidification as a therapeutic or preventive strategy in skin diseases. In this investigation, only three products, specifically developed for the acidifica- 
tion of the skin, showed a buffering capacity $>1$. The majority of the products had a low or very low buffering capacity $(<0.3)[26]$.

In our study, we analyzed and demonstrated the clinical benefit of 3 products on skin $\mathrm{pH}$, skin barrier and skin hydration, which all have an absolute $\mathrm{pH} \leq 4.5$ and buffer capacity $>0.70$, which can be considered as good quality criteria for an optimized preparation for skin acidification as Wohlrab and Gebert [9] described.

We demonstrated in our study that Vit $\mathrm{C}$ is able to decrease skin $\mathrm{pH}$ significantly, whereas Collagen Spray and Mask were able to maintain the healthy skin $\mathrm{pH}$ over a long term period of 4 weeks. Short term $\mathrm{pH}$ effects were analyzed by Blaak et al. [27] who tested o/w emulsions at $\mathrm{pH}$ values of 3.5, 4.0, 4.5 and 5.5 on the skin surface $\mathrm{pH}$ in elderly people $(80+)$ and middle aged adults ( 31 - 50 years old) after 120 min after single application. In middle aged adults (mean skin $\mathrm{pH}$ at study start 4.98 ) only a product with $\mathrm{pH} 3.5$ was able to reduce the skin $\mathrm{pH}$, whereas the product with $\mathrm{pH} 4.0$ and $\mathrm{pH} 4.5$ maintained the skin $\mathrm{pH}$. In aged skin (80+, mean skin $\mathrm{pH} 5.5$ ), application of $\mathrm{pH} 3.5$ and $\mathrm{pH} 4.0$ cream lead to a decreased skin $\mathrm{pH}$ below 5.0. The $\mathrm{pH} 4.5$ and $\mathrm{pH} 5.5$ emulsions also led to a decrease, but not below 5.0. Additionally, Blaak et al. analyzed the effect of an o/w emulsion at $\mathrm{pH}$ value 4.0 on skin surface $\mathrm{pH}$ in elderly photoaged or chronological aged skin on long-term basis, after 4 weeks. The product was able to reduce the skin $\mathrm{pH}$ over time. These findings are in accordance with our long-term findings, demonstrating that especially for subjects with higher baseline $\mathrm{pH}$ $(>5.0)$ a low $\mathrm{pH}$ value of the product $(\leq 4.5)$ is able to lower increased skin $\mathrm{pH}$ to a more healthy skin $\mathrm{pH}<5.0$. For subjects with already healthy skin $\mathrm{pH}(<5.0)$ a low $\mathrm{pH}$ value of products $(\leq 4.5)$ is able to maintain a physiological skin $\mathrm{pH}$.

The observed effect in our study of the tested product on skin $\mathrm{pH}$ is in line with other studies as well. Kilic et al. [28] compared a w/o emulsion ( $\mathrm{pH} 4)$ to a $\mathrm{pH} 5.8 \mathrm{w} / \mathrm{o}$ emulsion in elderly people with increased skin $\mathrm{pH}$ after 4 weeks. The $\mathrm{pH} 4$ w/o emulsion resulted in a significantly lower skin $\mathrm{pH}$ and increased skin hydration compared with the $\mathrm{pH} 5.8$ w/o emulsion. Behm et al. [5] showed similar results on elderly subjected after 4 -week treatment with a $\mathrm{pH} 4$ w/o emulsion. That treatment led to increased skin hydration and reduced skin $\mathrm{pH}$.

The mean skin $\mathrm{pH}$ value of our study population was $4.99 \pm 0.52$, although the inclusion criteria were age $>50$ years old. A direct correlation between aging and the $\mathrm{pH}$ measured on skin surface has been described [19] [29] [30] [31]. In a sample of 574 men and women aged 18 - 95 years, those over the age of 80 years showed higher $\mathrm{pH}$ levels on both the forehead and the cheek [32]. The increase in skin surface $\mathrm{pH}$ with aging interferes with some functions of the skin of the elderly and thus has an adverse effect. Depending on age and skin condition, appropriate galenic formulations should be used to address the above mentioned concerns of elderly skin [33]. Nevertheless the skin $\mathrm{pH}$ of our study population is not significantly increased and below 5.0. In the study of Blaak et al. [27] the elderly study group (80+) had a much higher skin $\mathrm{pH}$ (5.5) and the middle aged group $(31-50)$ had a skin $\mathrm{pH}$ of 4.98 , of which the latter is comparable to our 
values. This implies that only a product with a $\mathrm{pH}<4.0$ is able to decrease skin $\mathrm{pH}$ further. Subgroup analysis of our data, including only subjects with skin $\mathrm{pH}>5.0$ demonstrated, that all products have an acidification effect on the skin $\mathrm{pH}$ over a period of 4 weeks, which was significant for Vit C and Spray. The effect for Mask was not significant, but this maybe due to small subgroup population. Nevertheless, the tested products in our study, which all have an acidic $\mathrm{pH}$ $\leq 4.5$, are able to counteract an increased $\mathrm{pH}$. This is in agreement with a statement from Proksch [1], that products "with a $\mathrm{pH}$ more acidic than the 'physiologic' one, for example $\mathrm{pH}<4$, and an appropriate buffer system may be suitable for several kinds of skin conditions and skin diseases that exhibit an increased $\mathrm{pH}$ ".

Maintaining an acidic $\mathrm{pH}$ of the stratum corneum is an important part of the skin's protective system and creates a hostile environment for colonization by pathogenic microorganisms. An acidic skin $\mathrm{pH}$ plays a crucial role in maintaining a healthy skin microbiome. It supports the growth of the resident physiological microflora and helps to suppress the colonization of pathogenic microbes. Several common skin diseases show variations of the skin $\mathrm{pH}$ value, which leads to disorders of the skin microbiome and subsequently to infections and inflammations [34]. Therefore those products with a more acidic $\mathrm{pH}$ are shown to reduce the skin $\mathrm{pH}$, improve skin barrier and improve the physiological microbiome as compared with products with a higher $\mathrm{pH}$ [1]. The tested products in our study are good candidates to maintain and achieve a healthy skin $\mathrm{pH}$ and therefore improved physiological microbiome. But further investigations are needed to proof the influence of these products on skin microbiome.

It has been demonstrated that both the skin barrier function and the skin hydration is influenced by skin $\mathrm{pH}$. We demonstrated in our study that Spray and Mask improve skin hydration, whereas Vit C had no influence on skin hydration. The increase of skin hydration is in line with other studies mentioned above. Behm et al. [5] and Kilic et al. [28] received similar results for skin hydration when treating elderly people with a $\mathrm{pH} 4$ w/o emulsion. It has to be mentioned that we did not expect an improvement of skin hydration for Vit $\mathrm{C}$ as it is intended to be used as an anti-oxidative ingredient, influencing different skin processes like pigmentation and collagen synthesis, but not as a full treatment product. The recommended use of $\mathrm{t} V$ it $\mathrm{C}$ is in conjunction with a moisturizer, which has not been used this way in this study. Additionally, the study set up excluded the use of any other body lotion or other hydrating cosmetic products in the test area. Therefore, the stable skin hydration seen with Vit $\mathrm{C}$ is within expectations.

Additional to the clear improvement and maintenance in skin $\mathrm{pH}$, a slight, not significant increase in TEWL in all treated and untreated areas was also observed. It should be noted that no clear consensus on the influence of age on TEWL exists in the published work. Both unchanged values for TEWL [31] [35] and subnormal values for TEWL [36] in aged skin have been reported. In line with the observation in this study, Blaak et al. [27] reported a slight, non-significant 
TEWL increase after treatment with a $\mathrm{pH} 4$ product.

The literature demonstrates that not every product with a low $\mathrm{pH}$ is capable of restoring skin $\mathrm{pH}$ and physiology. This is because galenic formulation and also the buffer capacity system used in a cosmetic product is of utmost importance. In this study, we used for Mask a lactic acid buffer system. Preclinical and clinical data for topical use of lactic acid is available [37] [38] [39] [40], demonstrating that lactic acid acidifies the superficial layers [22]. We showed that although the $\mathrm{pH}$ of the product is 4.33 and not below $\mathrm{pH} 4$, the skin $\mathrm{pH}$ is slightly reduced. Subgroup analysis ( $\mathrm{pH}>5$ at baseline) demonstrates a bigger effect in skin acidification, although this reduction is not significant, potentially due to a small study population. Nevertheless the product is able to maintain a healthy skin $\mathrm{pH}$ likely because of the good combination of product $\mathrm{pH}$ and buffer capacity.

The results of our study show that long-term acidic skin care products formulated with $\mathrm{pH} \leq 4.5$ with an adequate buffer capacity can normalize an elevated skin $\mathrm{pH}$ and maintain a physiological skin $\mathrm{pH}$, thus supporting physiological skin function. Additional studies are needed to confirm these effects in the elderly and in other indications such as diseased skin, and to analyze the impact on skin microbiome. The three products tested are promising candidates for skin acidification and thus for supporting and adjusting physiological skin function.

\section{Acknowledgements}

The study was funded by Medskin Solutions Dr. Suwelack AG, Germany.

\section{Conflicts of Interest}

The authors declare no conflicts of interest regarding the publication of this paper.

\section{References}

[1] Proksch, E. (2018) Buffering Capacity. Current Problems in Dermatology, 54, 11-18. https://doi.org/10.1159/000489513

[2] Bandier, J., Johansen, J.D., Petersen, L.J. and Carlsen, B.C. (2014) Skin pH, Atopic Dermatitis, and Filaggrin Mutations. Dermatitis, 25, 127-129.

https://doi.org/10.1097/DER.0000000000000045

[3] Ali, S.M. and Yosipovitch, G. (2013) Skin pH: From Basic Science to Basic Skin Care. Acta Dermato- Venereologica, 93, 261-267. https://doi.org/10.2340/00015555-1531

[4] Schmid-Wendtner, M.H. and Korting, H.C. (2006) The pH of the Skin Surface and Its Impact on the Barrier Function. Skin Pharmacology and Physiology, 19, 296-302. https://doi.org/10.1159/000094670

[5] Schreml, S., Zeller, V., Meier, R.J., Korting, H.C., Behm, B., Landthaler, M., et al. (2012) Impact of Age and Body Site on Adult Female Skin Surface pH. Dermatology, 224, 66-71. https://doi.org/10.1159/000337029 
[6] Segger, D., Aßmus, U., Brock, M., Erasmy, J., Finkel, P., Fitzner, A., et al. (2008) Multicenter Study on Measurement of the Natural pH of the Skin Surface. International Journal of Cosmetic Science, 30, 75. https://doi.org/10.1111/j.1468-2494.2007.00403_1.x

[7] Levin, J. and Maibach, H. (2008) Human Skin Buffering Capacity: An Overview. Skin Research and Technology, 14, 121-126. https://doi.org/10.1111/j.1600-0846.2007.00271.x

[8] Choi, E.H. (2018) Gender, Age, and Ethnicity as Factors That Can Influence Skin pH. Current Problems in Dermatology, 54, 48-53. https://doi.org/10.1159/000489517

[9] Wohlrab, J. and Gebert, A. (2018) pH and Buffer Capacity of Topical Formulations. Current Problems in Dermatology, 54, 123-131. https://doi.org/10.1159/000489526

[10] Lambers, H., Piessens, S., Bloem, A., Pronk, H. and Finkel, P. (2006) Natural Skin Surface $\mathrm{pH}$ Is on Average below 5, Which Is Beneficial for Its Resident Flora. International Journal of Cosmetic Science, 28, 359-370. https://doi.org/10.1111/j.1467-2494.2006.00344.x

[11] Noble, W.C. (1993) Staphylococci on the Skin. In: The Skin Microflora and Microbial Skin Disease, Cambridge University Press, Cambridge, 135-152. https://doi.org/10.1017/CBO9780511527012.007

[12] Holland, K.T. and Bojar, R.A. (2002) Cosmetics: What Is Their Influence on the Skin Microflora? American Journal of Clinical Dermatology, 3, 445-449. https://doi.org/10.2165/00128071-200203070-00001

[13] Farage, M.A., Hood, W., Berardesca, E. and Maibach, H. (2018) Intrinsic and Extrinsic Factors Affecting Skin Surface pH. Current Problems in Dermatology, 54, 33-47. https://doi.org/10.1159/000489516

[14] Danby, S.G. and Cork, M.J. (2018) pH in Atopic Dermatitis. Current Problems in Dermatology, 54, 95-107. https://doi.org/10.1159/000489523

[15] Schurer, N. (2018) pH and Acne. Current Problems in Dermatology, 54, 115-122. https://doi.org/10.1159/000489525

[16] Proksch, E., Soeberdt, M., Neumann, C., Reich, H. and Abels, C. (2018) 670 Topically Applied Buffers of Different $\mathrm{pH}$ and Composition Influence Skin $\mathrm{pH}$, Barrier Repair, Epidermal Differentiation, and Inflammation. Journal of Investigative Dermatology, 138, S114. https://doi.org/10.1016/j.jid.2018.03.679

[17] Oman, S.V. and Ritonja, A. (1984) Die Pufferkapazität kosmetischer und pharmazeutischer Emulsionen. Parfümerie und Kosmetik, 65, 186-189.

[18] Hyde, R., Puy, R.J., Raub, W.F. and Forster, R.E. (1968) Rate of Disappearance of Labeled Carbon Dioxide from the Lungs of Humans during Breath Holding: A Method for Studying the Dynamics of Pulmonary $\mathrm{CO}_{2}$ Exchange. Journal of Clinical Investigation, 47, 1535-1552. https://doi.org/10.1172/JCI105846

[19] Schreml, S., Meier, R.J., Weiss, K.T., Cattani, J., Flittner, D., Gehmert, S., et al. (2012) A Sprayable Luminescent $\mathrm{pH}$ Sensor and Its Use for Wound Imaging in $\mathrm{Vi}$ vo. Experimental Dermatology, 21, 951-953. https://doi.org/10.1111/exd.12042

[20] Elias, P.M. and Wakefield, J.S. (2014) Mechanisms of Abnormal Lamellar Body Secretion and the Dysfunctional Skin Barrier in Patients with Atopic Dermatitis. The Journal of Allergy and Clinical Immunology, 134, 781-791e1. https://doi.org/10.1016/j.jaci.2014.05.048

[21] Pankratov, V.G. (1970) Study of the $\mathrm{pH}$ and $\mathrm{rH} 2$ of the Skin Surface in Patients with Psoriasis and Eczema. Vestnik Dermatologii i Venerologii, 44, 20-25. 
[22] Ohman, H. and Vahlquist, A. (1998) The pH Gradient over the Stratum Corneum Differs in X-Linked Recessive and Autosomal Dominant Ichthyosis: A Clue to the Molecular Origin of the "Acid Skin Mantle"? Journal of Investigative Dermatology, 111, 674-677. https://doi.org/10.1046/j.1523-1747.1998.00356.x

[23] Proksch, E., Jensen, J.M. and Elias, P.M. (2003) Skin Lipids and Epidermal Differentiation in Atopic Dermatitis. Clinics in Dermatology, 21, 134-144. https://doi.org/10.1016/S0738-081X(02)00370-X

[24] Shi, V.Y., Tran, K. and Lio, P.A. (2012) A Comparison of Physicochemical Properties of a Selection of Modern Moisturizers: Hydrophilic Index and pH. Journal of Drugs in Dermatology, 11, 633-636.

[25] Gunathilake, R., Schurer, N.Y., Shoo, B.A., Celli, A., Hachem, J.P., Crumrine, D., et al. (2009) $\mathrm{pH}$-Regulated Mechanisms Account for Pigment-Type Differences in Epidermal Barrier Function. Journal of Investigative Dermatology, 129, 1719-1729. https://doi.org/10.1038/jid.2008.442

[26] Surber, C., Humbert, P., Abels, C. and Maibach, H. (2018) The Acid Mantle: A Myth or an Essential Part of Skin Health? Current Problems in Dermatology, 54, 1-10. https://doi.org/10.1159/000489512

[27] Blaak, J., Wohlfart, R. and Schürer, N.Y. (2011) Treatment of Aged Skin with a pH 4 Skin Care Product Normalizes Increased Skin Surface $\mathrm{pH}$ and Improves Barrier Function: Results of a Pilot Study. Journal of Cosmetics, Dermatological Sciences and Applications, 1, 50-58. https://doi.org/10.4236/jcdsa.2011.13009

[28] Kilic, A., Masur, C., Reich, H., Knie, U., Dahnhardt, D., Dahnhardt-Pfeiffer, S., et al. (2019) Skin Acidification with a Water-in-Oil Emulsion ( $\mathrm{pH}$ 4) Restores Disrupted Epidermal Barrier and Improves Structure of Lipid Lamellae in the Elderly. The Journal of Dermatology, 46, 457-465. https://doi.org/10.1111/1346-8138.14891

[29] Man, M.Q., Xin, S.J., Song, S.P., Cho, S.Y., Zhang, X.J., Tu, C.X., et al. (2009) Variation of Skin Surface pH, Sebum Content and Stratum Corneum Hydration with Age and Gender in a Large Chinese Population. Skin Pharmacology and Physiology, 22, 190-199. https://doi.org/10.1159/000231524

[30] Luebberding, S., Krueger, N. and Kerscher, M. (2013) Age-Related Changes in Skin Barrier Function-Quantitative Evaluation of 150 Female Subjects. International Journal of Cosmetic Science, 35, 183-190. https://doi.org/10.1111/ics.12024

[31] Luebberding, S., Krueger, N. and Kerscher, M. (2014) Age-Related Changes in Male Skin: Quantitative Evaluation of One Hundred and Fifty Male Subjects. Skin Pharmacology and Physiology, 27, 9-17. https://doi.org/10.1159/000351349

[32] Zlotogorski, A. (1987) Distribution of Skin Surface pH on the Forehead and Cheek of Adults. Archives of Dermatological Research, 279, 398-401. https://doi.org/10.1007/BF00412626

[33] Abels, C. and Angelova-Fischer, I. (2018) Skin Care Products: Age-Appropriate Cosmetics. Current Problems in Dermatology, 54, 173-182. https://doi.org/10.1159/000489531

[34] Rippke, F., Berardesca, E. and Weber, T.M. (2018) pH and Microbial Infections. Current Problems in Dermatology, 54, 87-94. https://doi.org/10.1159/000489522

[35] Sato, N., Kitahara, T. and Fujimura, T. (2014) Age-Related Changes of Stratum Corneum Functions of Skin on the Trunk and the Limbs. Skin Pharmacology and Physiology, 27, 181. https://doi.org/10.1159/000353912

[36] Ghadially, R., Brown, B.E., Sequeira-Martin, S.M., Feingold, K.R. and Elias, P.M. (1995) The Aged Epidermal Permeability Barrier. Structural, Functional, and Lipid 
Biochemical Abnormalities in Humans and a Senescent Murine Model. Journal of Clinical Investigation, 95, 2281-2290. https://doi.org/10.1172/JCI117919

[37] Darlenski, R., Kazandjieva, J., Fluhr, J.W., Maurer, M. and Tsankov, N. (2014) Lactic Acid Sting Test Does Not Differentiate between Facial and Generalized Skin Functional Impairment in Sensitive Skin in Atopic Dermatitis and Rosacea. Journal of Dermatological Science, 76, 151-153.

https://doi.org/10.1016/j.jdermsci.2014.08.014

[38] Sahlin, A., Edlund, F. and Loden, M. (2007) A Double-Blind and Controlled Study on the Influence of the Vehicle on the Skin Susceptibility to Stinging from Lactic Acid. International Journal of Cosmetic Science, 29, 385-390. https://doi.org/10.1111/j.1468-2494.2007.00396.x

[39] Stiller, M.J., et al. (1996) Topical 8\% Glycolic Acid and 8\% L-Lactic Acid Creams for the Treatment of Photodamaged Skin. A Double-Blind Vehicle-Controlled Clinical Trial. Archives of Dermatology, 132, 631-636.

https://doi.org/10.1001/archderm.132.6.631

[40] Sourla, D., Dallas, P., Rekkas, D. and Choulis, N. (2003) Optimization of in Vitro Skin Permeation by Lactic Acid from Gel Formulations. Journal of Cosmetic Science, 54, 421-426. 